\title{
PEMBUATAN PROTOTIPE PENGERING BATUBARA UNTUK MENGURANGI MOISTURE CONTENT PADA PLTU
}

\author{
Wiji Mangestiono \\ Program Studi Diploma III Teknik Mesin \\ Fakultas Teknik Universitas Diponegoro
}

\begin{abstract}
Wiji Mangestiono, in paper prototype development of coal dryer to reduce moisture content on power plant explain that the percentage of coal use in the power industry in Indonesia has increased during the period of the last ten years. This policy is taken by the government by at least two considerations, namely: the higher world oil prices so that the price of electricity per kwh increase in addition Indonesia itself is the world's largest coal producer with serial number to six so that the transfer of fuel oil to the coal is considered very right. There is a fundamental problem that must be observed that coal mining in Indonesia in general have a low-rank quality with sub - categories butuminus and lignite which has a low calorific value (below $6100 \mathrm{kcal} / \mathrm{kg}$ ) and moisture content (moisture content) relatively high (40\%). This is exacerbated by the way the coal deposit which is usually placed on the page (coal yard). Low-rank coal with pores relatively greater will more easily absorb water during the rainy season so that the moisture content will be even greater. The use of coal in Rembang reached 1.3 million tons / year. Heat loss due to the use of coal with a high moisture content reaches 300 billion kcal per year or equivalent to coal with a calorific value of 50 thousand tons or the equivalent of cash also 30 billion rupiah. After observing the phenomenon in Rembang the researchers plan to create a prototype coal heaters with a capacity of $100 \mathrm{~kg} /$ hour in the hope of getting a concept to eliminate or minimize heat loss as described. Heating devices planned screw -shaped drum with a player in it which serves stirring granulated coal. The hot air is taken from the flue gas is sprayed into the drum. The independent variable of this study is the screw rotational speed and the speed and temperature of the hot air flow. Coal is expected after discharge from the dryer may have a water content below $10 \%$ as high quality coal (anthrasit).
\end{abstract}

Keyword : coal, moisture content, dryers

\section{LATAR BELAKANG}

Penggunaan batu bara dalam industri listrik di Indonesia semakin meningkat dimana instalasi pembangkit listrik yang didirikan pada satu dasa warsa terakhir selalu menggunakan bahan bakar batu bara. Kebijakan ini diambil oleh pemerintah berdasarkan setidaknya dua pertimbangan, pertama: harga minyak dunia yang semakin tinggi menyebabkan harga listrik per kwh meningkat, kedua : Indonesia sendiri adalah negara penghasil batubara terbesar dunia dengan nomer urut enam. Dengan demikian pengalihan penggunaan bahan bakar minyak bumi menuju batu bara dipandang sangat beralasan. Di Indonesia, batu bara merupakan bahan bakar utama selain solar (diesel fuel) yang telah umum digunakan pada banyak industri, dari segi ekonomi batu bara jauh lebih hemat dibandingkan solar, dengan perbandingan sebagai berikut : harga solar Rp 0,74/kkal sedangkan batu bara hanya Rp 0,1/kkal.

Berkaitan dengan hal ini peneliti menangkap adanya permasalahan yang sangat mendasar yang harus dicermati, bahwa kualitas batu bara hasil tambang di Indonesia pada umumnya berada dalam kategori low-rank yaitu tergolong dalam jenis subbituminus $\left(\mathrm{C}_{137} \mathrm{H}_{97} \mathrm{O}_{9} \mathrm{NS}\right)$ dimana mempunyai nilai kalor rendah (di bawah 6100 kakal/kg) dan mempunyai kandungan air (moisture content) relatif tinggi (mencapai 40\%). Hal ini semakin diperparah dengan cara penyimpanan batu bara yang biasanya ditempatkan di halaman (coal yard). Batu bara low rank dengan pori-pori yang elatif lebih besar akan semakin mudah menyerap air pada waktu musim hujan sehingga kadar air akan menjadi lebih besar lagi (Jishan Liu, 2010).

Secara teoritis bisa dihitung kerugian kalor selama setahun pada PLTU Rembang akibat kadar air tinggi yaitu mencapai 300 milyar kkal atau senilai dengan batu bara 50 ribu ton atau juga senilai dengan uang 30 milyar rupiah.

Setelah mencermati fenomena pada PLTU Rembang peneliti berencana membuat prototipe pengering batu bara dalam skala kecil dengan harapan bisa mendapatkan konsep untuk meniadakan atau meminimalisir kerugian kalor seperti telah diuraikan. Diharapkan batu bara setelah keluar dari alat pengering memiliki kandungan air di bawah $10 \%$ sebagaimana batubara kualitas tinggi (anthrasit).

Lebih lanjut perlu dinyatakan disini bahwa penelitian ini bukanlah merupakan penelitian yang berdiri sendiri dan terpisah dengan penelitian terdahulu, akan tetapi mengacu dari penelitian serupa dengan disertai penyertaan pemikiran baru untuk mendapatkan hasil penelitian yang lebih baik.

Jaeh Yeon Park dkk (Jaeh, 2010) telah melakukan penelitian dengan judul "The Effect of Gas Temperature and Velocity on Coal Drying in Fluidized Bed Dryer”. Pada penelitian ini mereka berusaha untuk mengatasi permasalahan kualitas 
batu bara yang rendah serta kadar air yang tinggi. Mereka membuat pemanas dengan media uap dengan variabel temperatur dan kecepatan. Hasil yang mereka dapat adalah kadar air bisa turun mencapai 80 hingga 90\%.

Pada tahun 2011 para peneliti dari PLN Puslitbang Ketenagalistrikan berhasil membangun dan mengoperasikan alat pengering batubara skala laboratorium dengan kapasitas 1 ton batubara per jam. Proses pengeringan menggunakan gas buang (flue gas) dengan tujuan mengurangi resiko terbakar sendiri (self combustion) dan memanfaatkan panas dari gas buang tersebut. Pada uji coba pengeringan dengan temperatur flue gas $150{ }^{\circ} \mathrm{C}$, diperoleh kenaikan nilai kalor sebesar 500 - 600 kcal/kg, sedangkan jika temperatur pengeringan dinaikkan menjadi $160{ }^{\circ} \mathrm{C}$ diperoleh kenaikan nilai kalor hingga $900 \mathrm{kcal} / \mathrm{kg}$. Dengan keberhasilan tersebut direncanakan dapat dilakukan ujicoba untuk membangun alat yang sama dengan kapasitas yang lebih besar di lapangan.

Pada tahun 2011 laboratorium BPPT Serpong melakukan uji coba skala laboratorium terhadap alat pengering batubara. Alat yang diuji adalah Steam Tube Dryer yang memakai uap air sebagai pemanas. Uap air tersebut dialirkan pada pipa-pipa yang terdapat pada tabung berputar yang diisi batubara. Di luar negri produk alat tersebut telah beroperasi dan dipakai baik pada pembangkit listrik maupun cooking coal.

Penelitian yang dilakukan ini walaupun bertujuan sama yaitu mengeringkan batu bara dengan maksud untuk mengurangi moisture content akan tetapi menggunakan prinsip kerja yang berbeda. Pengeringan batu bara dilakukan dalam drum yang didalamnya terdapat pemutar atau pengaduk tipe screw selanjutnya gas panas disemprotkan (spray) ke dalam drum. Model seperti ini oleh peneliti diberi nama model drum-screwspray. Perpaduan fungsi dari screw dan spray dalam drum diharapkan dapat menyebabkan pemanasan menjadi lebih merata sehingga mampu mengurangi moisture content secara maksimal (di bawah 10\%). Kualitas batu bara dengan moisture content di bawah $10 \%$ adalah tergolong batu bara kualitas tinggi (setara anthrasit) sehingga efisiensi thermal pembangkit menjadi semakin tinggi.

Permasalahan yang akan dijawab melalui penelitian ini yaitu : Kualitas batu bara dalam kategori low-rank (sub-bituminus) mempunyai nilai kalor yang rendah (di bawah $6100 \mathrm{kkal} / \mathrm{kg}$ ) dan mempunyai kadar air (moisture content) yang tinggi (di atas 40\%). Kondisi ini menyebabkan kerugian yang cukup besar pada PLTU Rembang yaitu mencapai 300 milyar kkal atau setara dengan 50 ribu ton batu bara atau juga setara dengan uang 30 milyar rupiah per tahun. Berkaitan dengan hal itu perlu dilakukan upaya sehingga dapat meminimalisir kerugian tersebut.
Penelitian yang dilaksanakan ini bertujuan untuk menemukan metode dan alat yang tepat guna mengeringkan batu bara sebelum diumpankan (feeding) ke dalam pulverizer sehingga dapat menurunkan moisture content dari 40\% lebih menjadi di bawah $10 \%$. Usaha ini dilakukan dengan cara membuat sebuah prototipe alat pengering batu bara model drum - screw - spray. Diharapkan dengan penggunaan alat ini dapat membantu meningkatkan efisiensi termal pada instalasi pembangkit listrik. adalah :

Manfaat yang didapat dari penelitian ini

- Terciptanya prototipe pengering batu bara sebagai sebuah formulasi desain yang mantap sehingga dapat dikembangkan menjadi pengering batu bara dengan kapasitas besar sesuai kebutuhan. Sehingga dapat meningkatkan efisiensi thermal pada sistem pembangkit listrik di Indonesia. Dengan adanya peningkatan efisiensi thermal ini diharapkan dapat menekan biaya yang dikeluarkan oleh PLN untuk harga setiap Kwh.

- Publikasi jurnal nasional yang bermanfaat bagi peneliti lain atau mahasiswa maupun masyarakat yang membutuhkan informasi mengenai pengeringan batu bara.

\section{TINJAUAN PUSTAKA \\ Pembentukan batu bara}

Batu bara adalah salah satu bahan bakar fosil. Pengertian umumnya adalah batuan sedimen yang dapat terbakar, terbentuk dari endapan organik, utamanya adalah sisa-sisa tumbuhan dan terbentuk melalui proses pembatubaraan. Unsur-unsur utamanya terdiri dari karbon, hidrogen dan oksigen. Batu bara juga adalah batuan organik yang memiliki sifat-sifat fisika dan kimia yang kompleks yang dapat ditemui dalam berbagai bentuk. Analisis unsur memberikan rumus formula empiris seperti $\mathrm{C}_{137} \mathrm{H}_{97} \mathrm{O}_{9} \mathrm{NS}$ untuk bituminus dan $\mathrm{C}_{240} \mathrm{H}_{90} \mathrm{O}_{4} \mathrm{NS}$ untuk antrasit (Vishal,2013).

Pembentukan batu bara memerlukan kondisikondisi tertentu dan hanya terjadi pada era-era tertentu sepanjang sejarah geologi. Zaman Karbon, kira-kira 340 juta tahun yang lalu (jtl), adalah masa pembentukan batu bara yang paling produktif dimana hampir seluruh deposit batu bara (black coal) yang ekonomis di belahan bumi bagian utara terbentuk.

Pada Zaman Permian, kira-kira 270 jtl, juga terbentuk endapan-endapan batu bara yang ekonomis di belahan bumi bagian selatan, seperti Australia, dan berlangsung terus hingga ke Zaman Tersier (70 - 13 jtl) di berbagai belahan bumi lain.

Hampir seluruh pembentuk batu bara berasal dari tumbuhan. Jenis-jenis tumbuhan pembentuk batu bara dan umurnya adalah sebagai berikut: Alga, dari Zaman Pre-kambrium hingga Ordovisium dan bersel tunggal. Sangat sedikit endapan batu bara dari 
perioda ini. Silofita, dari Zaman Silur hingga Devon Tengah, merupakan turunan dari alga. Sedikit endapan batu bara dari perioda ini. Pterido fita, umur Devon Atas hingga Karbon Atas. Materi utama pembentuk batu bara berumur Karbon di Eropa dan Amerika Utara. Gimnospermae, kurun waktu mulai dari Zaman Permian hingga Kapur Tengah. Tumbuhan heteroseksual, biji terbungkus dalam buah, semisal pinus, mengandung kadar getah (resin) tinggi. Jenis Pteridospermae seperti gangamopteris dan glossopteris adalah penyusun utama batu bara Permian seperti di Australia, India dan Afrika.

\section{Pemanfaatan Batu Bara sebagai bahan bakar PLTU}

Saat ini, Indonesia menghadapi permasalahan dalam penyediaan energi diakibatkan kebutuhan energi nasional yang besar dan meningkat setiap tahun termasuk penyediaan energi untuk bahan bakar pada pembangkit listrik. Sementara itu, cadangan minyak bumi dan produksi BBM Indonesia semakin terbatas, sehingga sejak beberapa tahun terakhir nilai impor minyak bumi dan BBM Indonesia semakin meningkat. Pemerintah menaruh perhatian besar terhadap masalah listrik. Industri kelistrikan nasional sedang menghadapi permasalahan krusial, karena pasokan dan permintaan listrik tidak seimbang. Hal ini dapat terlihat dengan adanya pemadaman listrik di beberapa daerah di Indonesia dan adanya imbauan PT Perusahaan Listrik Negara (PLN) kepada pemakai untuk mengurangi penggunaan listrik,terutama di malam hari. Karena itu pemerintah berencana membangun pembangkit listrik baru dengan total kapasitas 25 ribu MW hingga 10 tahun kedepan untuk memenuhi kebutuhan listrik nasional yang sampai saat ini masih belum terpenuhi. Pembangunan pembangkit listrik non BBM dianggap penting untuk dilaksanakan. Salah satu alternatif yang dilakukan oleh pemerintah adalah dengan memanfaatkan batubara sebagai sumber bahan bakar, dimana direncanakan akan dilakukan perubahan pemanfaatan sumber energi untuk pembangkit listrik pada saat ini dan batubara akan mendapatkan persentase tertinggi. Pemanfaatan batubara sebagai bahan bakar pembangkit dijadikan sebagai pilihan utama dikarenakan Indonesia memiliki jumlah sumber daya batu bara yang sangat besar yaitu sekitar 613 miliyar Ton.

\section{Klasifikasi Batu Bara}

Batubara dibagi dalam empat kelas: anthracite, bituminous, sub-bituminous dan lignite (Yalcin Erik, 2010). Sebagian besar pembangkit baru yang dibangun akan menggunakan bahan bakar batubara low rank dikarenakan jumlah cadangannya masih cukup besar yaitu sekitar 86\% dari deposit batubara nasional. Cadangan batubara nasional terbesar adalah batubara muda (low rank) yaitu Sub-bituminus dan lignite dengan karakteristik nilai kalor rendah $(<6100 \mathrm{kcal} / \mathrm{kg})$ dan memiliki kandungan air (moisture content) relatif tinggi ( hingga 40\%).

Berdasarkan tingkat proses pembentukannya yang dikontrol oleh tekanan, panas dan waktu, batu bara umumnya dibagi dalam lima kelas: antrasit, bituminus, sub-bituminus, lignit dan gambut.

- Antrasit adalah kelas batu bara tertinggi, dengan warna hitam berkilauan (luster) metalik, mengandung antara 86\% - 98\% unsur karbon (C) dengan kadar air kurang dari 10\%.

- Bituminus mengandung 68 - 86\% unsur karbon (C) dan berkadar air 8-10\% dari beratnya. Kelas batu bara yang paling banyak ditambang di Australia.

- Sub-bituminus mengandung sedikit karbon dan banyak air, dan oleh karenanya menjadi sumber panas yang kurang efisien dibandingkan dengan bituminus.

- Lignit atau batu bara coklat adalah batu bara yang sangat lunak yang mengandung air $40 \%$ dari beratnya.

- Gambut, berpori dan memiliki kadar air di atas 75\% serta nilai kalori yang paling rendah.

\section{Pembersihan Kadar Berbahaya}

Ada beberapa zat yang berbahaya dalam batu bara, contoh sulfur, Fluorine dan sebagainya (Greta,2013). Sulfur adalah zat kimia kekuningan yang ada sedikit pada batu bara. Pada beberapa batu bara yang ditemukan di Ohio, Pennsylvania, West Virginia dan eastern states lainnya, sulfur terdiri dari 3 sampai $10 \%$ dari berat batu bara, beberapa batu bara yang ditemukan di Wyoming, Montana dan negara-negara bagian sebelah barat lainnya sulfur hanya sekitar 1/100ths (lebih kecil dari 1\%) dari berat batu bara. Penting bahwa sebagian besar sulfur ini dibuang sbelum mencapai cerobong asap.

Satu cara untuk membersihkan batu bara adalah dengan cara mudah yaitu memecah batu bara ke bongkahan yang lebih kecil dan mencucinya. Butir batu bara yang halus dengan ukuran 150 micron lebih mudah untuk dikurangi kadar airnya (Patil,2009). Beberapa sulfur yang ada sebagai bintik kecil di batu bara disebut sebagai pyritic sulfur karena ini dikombinasikan dengan besi menjadi bentuk iron pyrite, selain itu dikenal sebagai fool's gold dapat dipisahkan dari batu bara. Secara khusus pada proses satu kali, bongkahan batu bara dimasukkan ke dalam tangki besar yang terisi air , batu bara mengambang ke permukaan ketika kotoran sulfur tenggelam. Fasilitas pencucian ini dinamakan coal preparation plants yang berfungsi membersihkan batu bara dari pengotor-pengotornya.

Tidak semua sulfur bisa dibersihkan dengan cara ini, bagaimanapun sulfur pada batu bara adalah secara kimia benar-benar terikat dengan molekul karbonnya, tipe sulfur ini disebut organic sulfur, dan 
pencucian tak akan menghilangkannya. Beberapa proses telah dicoba untuk mencampur batu bara dengan bahan kimia yang membebaskan sulfur terlepas dari molekul batu bara, tetapi kebanyakan proses ini sudah terbukti terlalu mahal. Sampai sekarang ini para ilmuwan masih bekerja keras untuk mengurangi biaya dari proses pencucian kimia ini.

Kebanyakan pembangkit tenaga listrik modern dan semua fasilitas yang dibangun setelah 1978 - telah diwajibkan untuk mempunyai alat khusus yang dipasang untuk membuang sulfur dari gas hasil pembakaran batu bara sebelum gas ini naik menuju cerobong asap. Alat ini adalah flue gas desulfurization units, atau juga disebut scrubbers.

\section{METODE PENELITIAN}

Penelitian yang dilaksanakan ini menggunakan metode eksperimen murni (pure experiment). Kegiatan penelitian dilakukan dengan pendekatan mencoba gagal dan memperbaiki (trial and error). Pembahasan lebih lanjut dicantumkan pada uraian item-item di bawah ini.

\section{Bahan}

Bahan yang diperlukan dalam penelitian ini adalah batu bara kualitas low rank yaitu sub bituminus dan lignite. Kondisi asal adalah berbentuk bongkahan selanjutnya dihancurkan dan diayak dengan kekasaran mesh 200. Bahan yang akan diteliti ini mempunyai kadar antara 40 hingga $60 \%$.

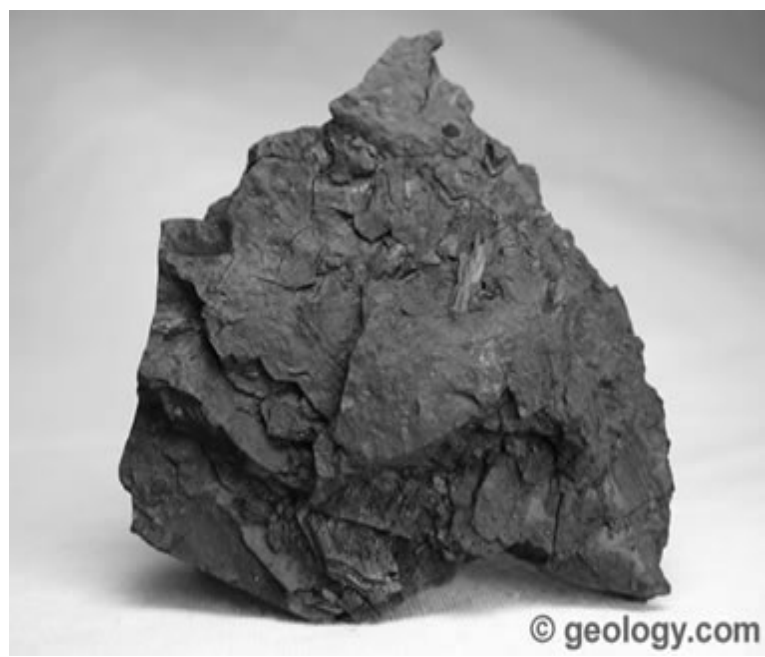

Gambar 1. Batu bara jenis Lignite

Alat

Alat yang diperlukan dalam penelitian ini meliputi berbagai alat yang dibutuhkan dalam pengambilan data yaitu :

- Moisture Content seri MC-7825PS

Alat ini digunakan untuk mengukur kadar air batu bara baik sebelum proses pengeringan maupun sesudah proses pengeringan. Kapasitas pengukuran yang terjangkau oleh alat ini adalah 0 hingga $80 \%$ moisture.
- Venturi Tube

Alat ini digunakan untuk mengukur kecepatan aliran udara panas yang digunakan sebagai media pengering batu bara. Posisi pemasangan diletakkan sebelum penyemprotan (spray) masuk ke dalam drum pemanas.

- Regulator Frekwensi

Alat ini digunakan untuk mengatur frekwensi motor listrik van penghisap udara panas dan motor listrik pemutar screw pengaduk agar putaran motor listrik yang dimaksudkan bisa diatur. Pengaturan ini bertujuan untuk mengatur kapasitas pengeringan dan tingkat kekeringan yang bisa dicapai.

- Thermokopel

Alat ini digunakan untuk mengatur pemanasan udara hingga mencapai nilai temperatur udara yang dikehendaki. Alat ini akan secara otomatis melakukan pemutusan dan penyambungan hubungan elemen pemanas udara sehingga udara pemanas dapat diatur temperaturnya.

\section{Variabel Penelitian}

Variabel bebas dalam penelitian ini adalah sebagai berikut:

- Kecepatan udara pemanas, putaran poros pengaduk (screw), temperatur udara pemanas. Ke tiga variabel bebas di atas akan diteliti pengaruhnya terhadap variabel tergantung. Agar pengaruhnya tidak bias maka beberapa variabel harus dikendalikan.

- Variabel Rambang

Tingkat kekeringan udara pemanas dalam hal ini dianggap sebagai variabel rambang dan diabaikan pengaruhnya.

- Variabel Kendali

Tergolong sebagai variabel kendali dalam hal ini adalah voltase listrik PLN. Perubahan voltase bisa diakibatkan oleh perubahan voltase jaringan PLN atau juga karena perubahan beban dimana penelitian dilaksanakan. Untuk mengendalikan pengaruh perubahan voltase yang akan berpengaruh secara bias terhadap temperatur pemanas, putaran screw, kecepatan aliran udara pemanas maka digunakan voltage regulator dengan kapasitas 2000 watt.

- Variabel Tergantung

Adalah variabel yang tergantung terhadap variabel bebas dimana menggambarkan hasil penelitian yang didapatkan. Dalam penelitian ini yang tergolong sebagai variabel tergantung adalah : Moisture content batu bara.

\section{Langkah Penelitian}

Pembuatan prototipe pengering batu bara model drum-screw-spray ditunjukkan pada gambar berikut ini. Pemanas udara dilakukan dengan pipa yang dililit nikelin. Arus listrik mengalir menuju 
pipa pemanas dikendalikan oleh termokopel sehingga temperatur udara pemanas bisa didapatkan secara stabil sesuai yang dikehendaki sebab tranduser panas dipasang pada kotak penampung udara panas. Selanjutnya udara panas disemprotkan oleh van menuju drum pemanas batu bara. Batu bara masuk ke drum pemanas melalui hover yang dipasang pada sisi kanan drum selanjutnya diaduk dan didorong opleh screw kearah kiri. Selama batu bara bergeser kearah kiri dan akhirnya keluar dari drum bersama dengan itu terjadi pemindahan panas yang dilakukan oleh udara pemanas. Suhu udara pemanas yang berada di atas $110^{\circ} \mathrm{C}$ menyebabkan kandungan air pada batubara menguap sehingga kadar air batubara meninggalkan drum menjadi lebih rendah dan diharapkan dapat mencapai di bawah $10 \%$. Kecepatan putar screw mengatur waktu pemanasan dan kapasitas pemanasan. Prototype alat ini ditunjukkan pada gambar 2.

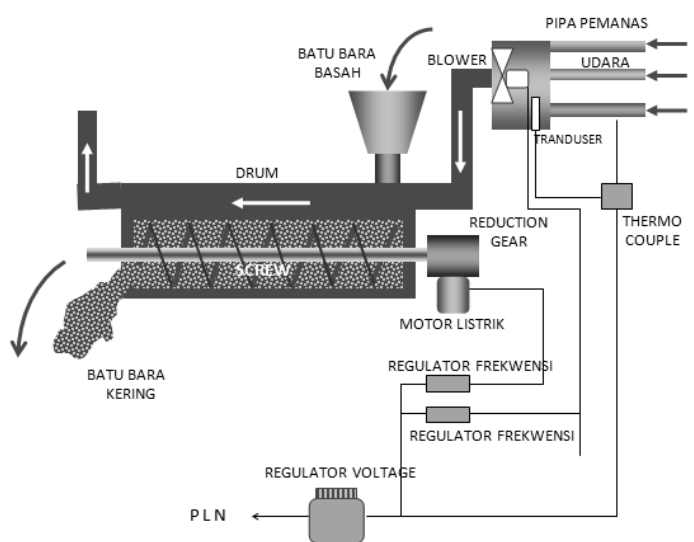

Gambar 2. Prototipe pengering batubara

\section{Pengambilan Data} adalah

Data yang diambil dalam penelitian ini

- Kecepatan aliran udara pemanas, diukur dengan flowmeter tipe venturi tube. Pengukuran dilakukan dengan mencatat tekanan pada upstream dan downstream selanjutnya dianalisa dengan rumus

$$
\mathrm{V}^{2}=\mathrm{dP}
$$

- Temperatur udara pemanas, diukur dan diatur dengan termokopel dengan pembacaan digital.

- Putaran poros rotor, diukur dengan tachometer.

- Kadar air batu bara sebelum dan sesudah pemanasan, diukur dengan menggunakan moisture content tipe MC-7825PS.

- Massa batu bara setelah pengeringan, diukur dengan timbangan.

\section{Analisis Data}

Analisis data dilakukan dengan metode grafis. Data yang diolah disajikan dalam bentuk grafik meliputi :
- Grafik hubungan antara kecepatan screw, kecepatan udara pemanas terhadap kadar air pada temperatur udara pemanas $110^{\circ} \mathrm{C}$.

- Grafik hubungan antara kecepatan screw, kecepatan udara pemanas dengan kadar air pada temperatur udara pemanas $130^{\circ} \mathrm{C}$.

- Grafik hubungan antara kecepatan screw, kecepatan udara pemanas dengan kadar air pada temperatur udara pemanas $150^{\circ} \mathrm{C}$.

- Selanjutnya dari grafik yang didapat ditarik kesimpulan mengenai setting pengoperasian yang terbaik yaitu :

- $\quad$ Berapakah putaran screw yang terbaik?

- Berapakah kecepatan udara pemanas yang terbaik?

- Berapakah temperatur udara pemanas yang terbaik?

\section{HASIL PENELITIAN}

Setelah penelitian ini dilaksanakan dan menghasilkan prototipe pengering batu bara yang baik dengan tolok ukur dapat menghasilkan batu bara dengan moisture content di bawah 10\%, maka peneliti berencana akan melakukan penelitian serupa dengan disertai perbaikan-perbaikan tertentu dalam skala yang besar dengan kapasitas yang memadai sesuai kebutuhan PLTU Rembang yaitu 150 ton/jam. Lebih dari itu peneliti bermaksud melibatkan langsung PLTU Rembang dalam pembuatan alat pengering batu bara dimana akan memberikan keuntungan secara langsung pada PLTU Rembang. Keuntungan yang didapatkan adalah :

Dapat dilakukan penghematan batu bara sebanyak 50 ribu ton per tahun atau setara dengan penghematan kalor 300 milyar kkal per tahun dimana nilai ini setara dengan uang 30 milyar rupiah juga dapat dilakukan peningkatan efisiensi termal instalasi pembangkit listrik pada PLTU Rembang mencapai kurang lebih 30\%.

\section{- Hipotesis}

Peneliti tidak melakukan uji hipotesis dalam penelitian ini. Keberhasilan penelitian ini diukur dari pengujian batu bara setelah proses pengeringan dimana bila kadar air batu bara (moisture content) di bawah $10 \%$ maka prototipe yang diteliti dinyatakan berhasil. Perlu ditandaskan disini bahwa kadar air batu bara di bawah 10\% adalah setara dengan kategori batu bara high rank. Lebih lanjut data yang didapat akan dianalisis secara grafis sehingga dapat ditarik kesimpulan pada akhir penelitian.

\section{KESIMPULAN}

- Penelitian yang dilakukan mampu memanaskan batubara hingga mencapai moisture content 9,8 $\%$ atau berada di bawah $10 \%$ sesuai dengan yang direncanakan.

- Meskipun kapasitas yang dihasilkan relatif masih rendah yaitu $10 \mathrm{Kg} / \mathrm{jam}$ akan tetapi masih bisa ditingkatkan sehingga mencapai 
150 ton/jam sesuai dengan kebutuhan PLTU Rembang.

\section{DAFTAR PUSTAKA}

1. Chikerema.Pheneas, Moys.Michael, Effects of Particle Size, Shape, and Density on the Performance of an Air Fluidized Bed in Dry Coal Beneficiation, International Journal of Coal Preparation and Utilization, Vol : 32 (2012) p : 80-94.

2. Eskenazy Greta, Shifeng Dai, Xiao Li, Fluorine in Bulgarian coals, International Journal of Coal Geology,Vol : 105(2013)p:1623.

3. Firth.Bruce, O'Brien.Mike, Mc Nally.Clint, Medium Quality and DMC Performance :Influence of Small Coal, International Journal of Coal Preparation and Utilization, vol : 31 (2011) p : 346 - 354

4. Karacan.J.P., Ulery, Goodman, A numerical evaluation on the effects of impermeable faults on degasification efficiency and methane emissions during underground coal mining, International Journal Of Coal Geology, Vol : 75 (2008), p : 195 - 203.

5. Liu.Jishan, Zhongwei Chen, Derek Elsworth, Xiexing Miao, Xianbiao Mao, Evaluation of stress-controlled coal swelling processes, International Journal Of Coal Geology, Vol: 85 (2010), p:446-455.

6. Patil' D. P., Taulbee, Parekh, Briquetting of Coal Fines and Sawdust Effect of Particle-
Size Distribution, International journal of Coal Preparation and Utilization, Vol 29 (2009), p : $251-264$

7. Park.Yeon Jaeh, Shun.Dowan, Bae.Dal He, Lee.Shi Yun, Seo.Jeong Hak,2010, The Effect of Gas Temperature and Velocity on Coal Dying in Fluidized Bed Dryer, Han Yang University, Korea.

8. Sahu.A.K., Biswal.S.K., Parida.A., Development of Air Dense Medium Fluidized Bed Technology For Dry Beneficiation of Coal - A Review, International Journal of Coal Preparation and Utilization, Vol : 29 (2009) p : 216-241.

9. Vishal.P, Ranjith P.G., Singh,P.G., $\mathbf{C O}_{2}$ permeability of Indian bituminous coals: Implications for carbon sequestration, International Journal Of Coal Geology, Vol:105(2013), p: 36-47.

10. Xuliang.Yang, Yuemin.Zhao, Gongmin. Li, Luo Zhenfu, Chen Zengqiang' Liang Chuncheng, Establishment and Evaluation of a United Dry Coal Beneficiation System, International Journal of Coal Preparation and Utilization, Vol : 32 (2012) p : 95-102.

11. Yalçın. Erik, Sancar.S., Relationships between coal-quality and organicgeochemical parameters: A case study of the Hafik coal deposits (Sivas Basin, Turkey), International Journal Of Coal Geology,Vol:105(2013),p:48-59 